\title{
Structural Properties of Benzimidazole Cavitand and its Selective Recognition towards 4-Methylbenzamide over 4-Methylanilide
}

\author{
Heung-Jin Choi, * Yeon Sil Park, Jie Song, Seok Ju Youn, Hong-Seok Kim, Sung-Hoon Kim, ' \\ Kwangnak Koh $h^{+}$and Kyungsoo Paek ${ }^{\mathcal{S}}$ \\ Department of Applied Chemistry, Kyungpook National University, Daegu 702-701, Korea, \\ ${ }^{\dagger}$ Department of Dyeing and Finishing, Kyungpook National University, Daegu 702-701, Korea, \\ ${ }^{\ddagger}$ College of Pharmacy, Pusan National University, Busan 609-735, Korea, CAMDRC and \\ ${ }^{\S}$ Department of Chemistry, Soongsil University, Seoul 156-743, Korea
}

choihj@knu.ac.kr

\section{Supporting Information}

\section{Contents}

Figure 1. The ${ }^{1} \mathrm{H}$ NMR spectra in $\mathrm{CDCl}_{3}$ at room temperature: (a) $\mathbf{5} \cdot 4 \mathrm{CF}_{3} \mathrm{CO}_{2} \mathrm{H}$; (b) $\mathbf{5} \cdot 4 \mathrm{CH}_{3} \mathrm{CO}_{2} \mathrm{H}$; (c) $5 \cdot 4 \mathrm{CH}_{3} \mathrm{OH}$.

Figure 2. The ${ }^{1} \mathrm{H}$ NMR spectra of Benzimidazole Cavitand 5 in $\mathrm{CDCl}_{3} / \mathrm{CD}_{3} \mathrm{OD}(9: 1)$

Figure 3. The ${ }^{1} \mathrm{H}$ NMR spectra of Benzimidazole Cavitand $5 \cdot 4 \mathrm{CF}_{3} \mathrm{COOH}$ in $\mathrm{CDCl}_{3}$.

Figure 4. The ${ }^{1} \mathrm{H}$ NMR spectra of Benzimidazole Cavitand $\mathbf{5} \cdot 4 \mathrm{CH}_{3} \mathrm{COOH}$ in $\mathrm{CDCl}_{3}$.

Figure 5. The ${ }^{1} \mathrm{H}$ NMR spectra of Benzimidazole Cavitand 5.4MeOH in $\mathrm{CDCl}_{3}$.

Figure 6. ${ }^{1} \mathrm{H}$ NMR Spectra of Benzimidazole Cavitand 5 and 4-Methyl- $N$-4-tolylbenzamide 6 in $\mathrm{CD}_{3} \mathrm{OD} /$ mesitylene- $_{12}(1: 19, \mathrm{v} / \mathrm{v})$.

Figure 7. ${ }^{1} \mathrm{H}$ NMR Spectra of Benzimidazole Cavitand 5 and 4-Methyl- $N$-4-tolylbenzamide 6 in water-saturated $\mathrm{CDCl}_{3}$.

Figure 8. ${ }^{1} \mathrm{H}$ NMR Spectra of Benzimidazole Cavitand 5 and N,4-Dimethylbenzamide 7 in watersaturated $\mathrm{CDCl}_{3}$.

Figure 9. ${ }^{1} \mathrm{H}$ NMR Spectra of Benzimidazole Cavitand 5 and $N$-4-tolylacetamide 8 in watersaturated $\mathrm{CDCl}_{3}$. 


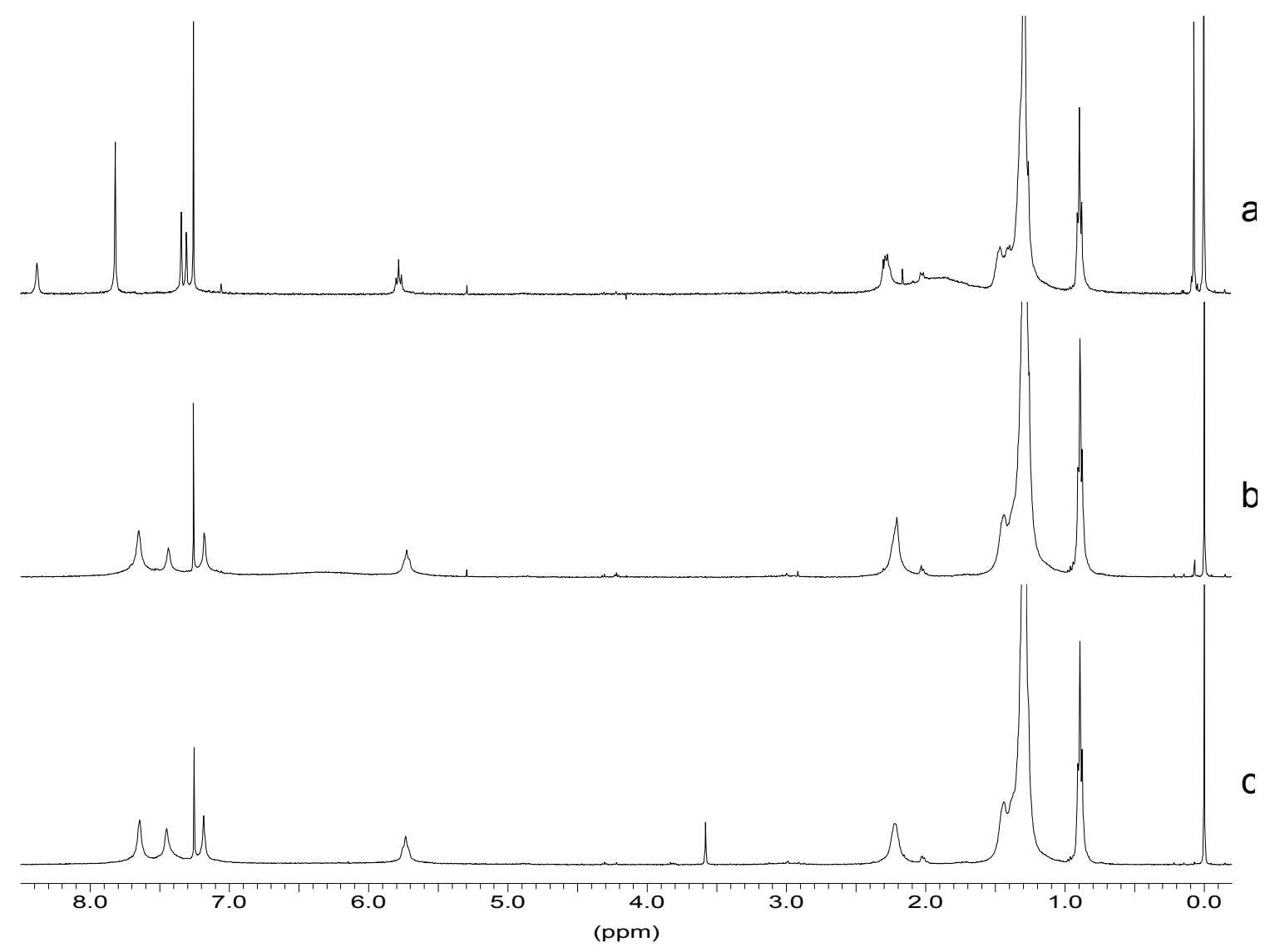

Figure 1. The ${ }^{1} \mathrm{H}$ NMR spectra in $\mathrm{CDCl}_{3}$ at room temperature: (a) $5 \cdot 4 \mathrm{CF}_{3} \mathrm{CO}_{2} \mathrm{H}$; (b) $\mathbf{5} \cdot 4 \mathrm{CH}_{3} \mathrm{CO}_{2} \mathrm{H}$; (c) $5 \cdot 4 \mathrm{CH}_{3} \mathrm{OH}$. 


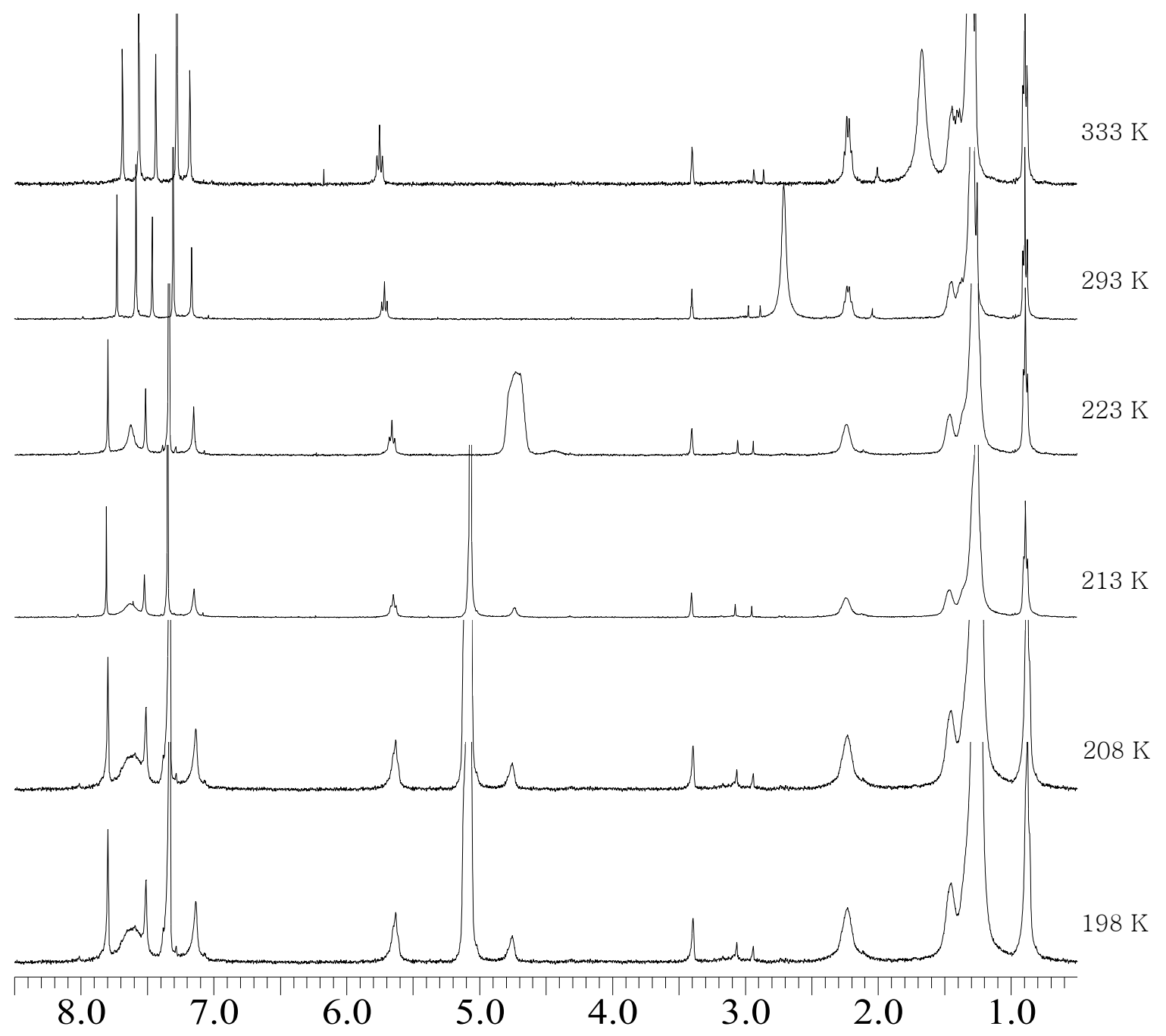

Figure 2. The ${ }^{1} \mathrm{H}$ NMR spectra of Benzimidazole Cavitand 5 in $\mathrm{CDCl}_{3} / \mathrm{CD}_{3} \mathrm{OD}$ (9:1) 


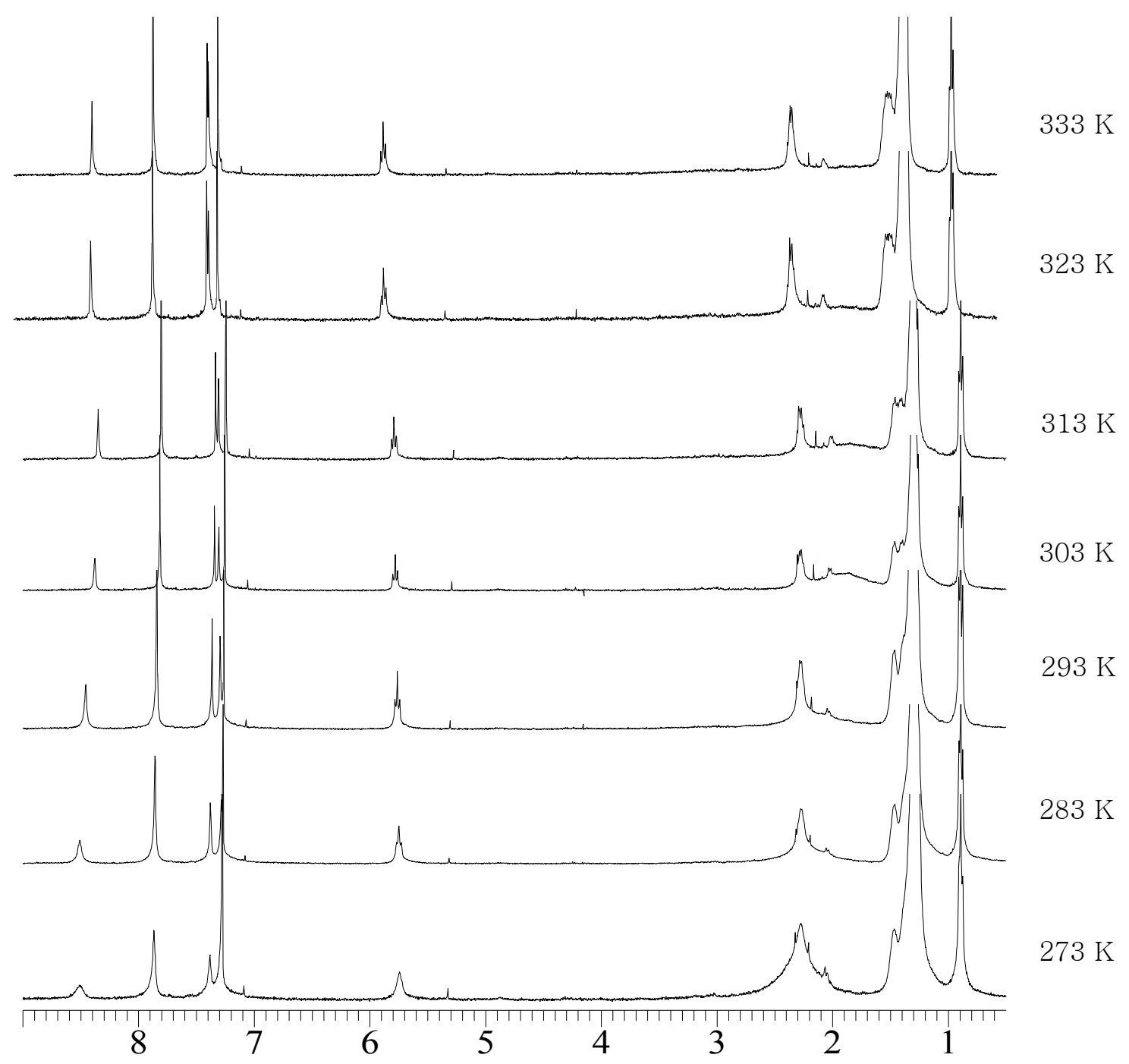

Figure 3. The ${ }^{1} \mathrm{H}$ NMR spectra of Benzimidazole Cavitand $\mathbf{5} \cdot 4 \mathrm{CF}_{3} \mathrm{COOH}$ in $\mathrm{CDCl}_{3}$. 


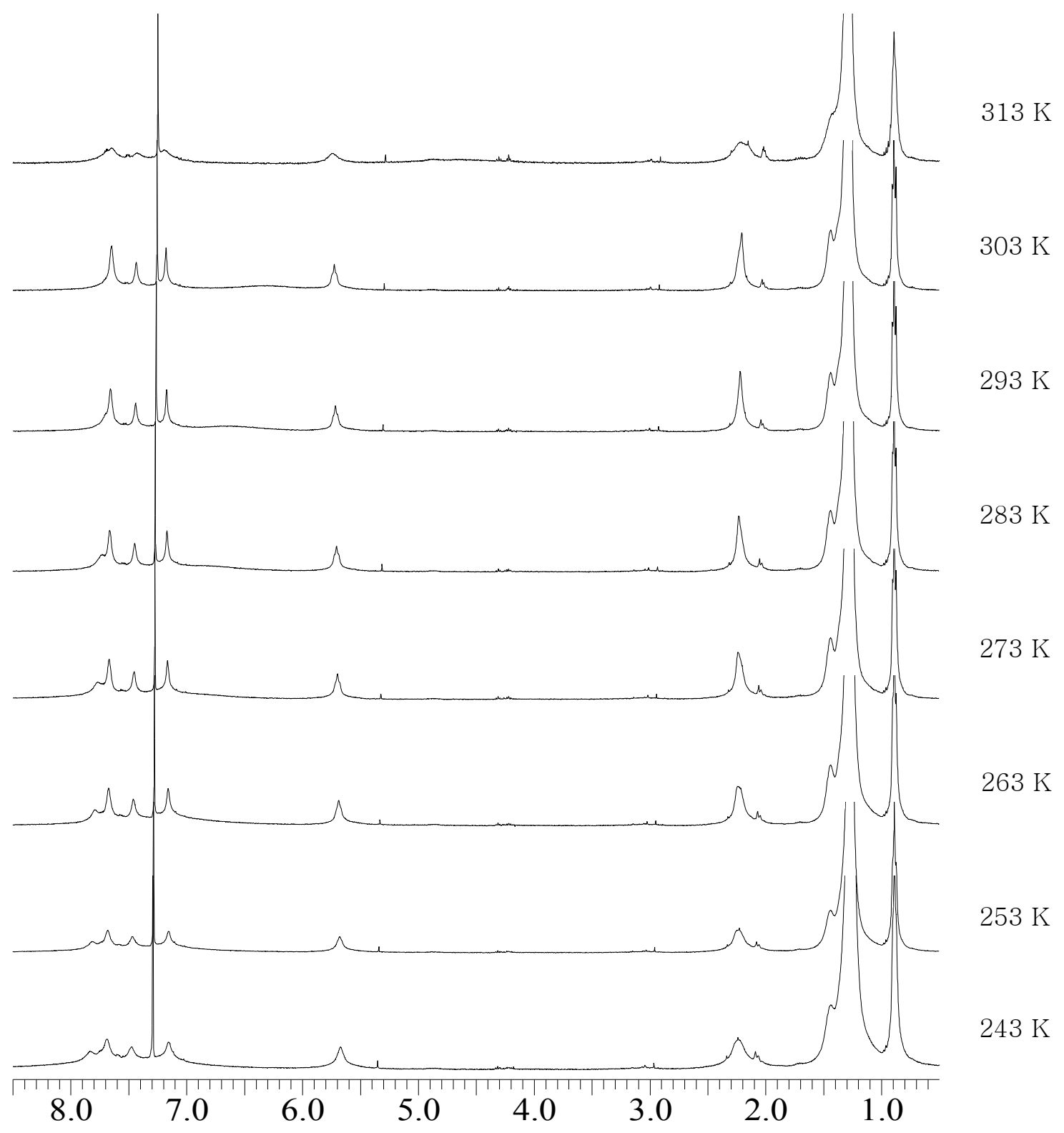

Figure 4. The ${ }^{1} \mathrm{H}$ NMR spectra of Benzimidazole Cavitand $5 \cdot 4 \mathrm{CH}_{3} \mathrm{COOH}$ in $\mathrm{CDCl}_{3}$. 


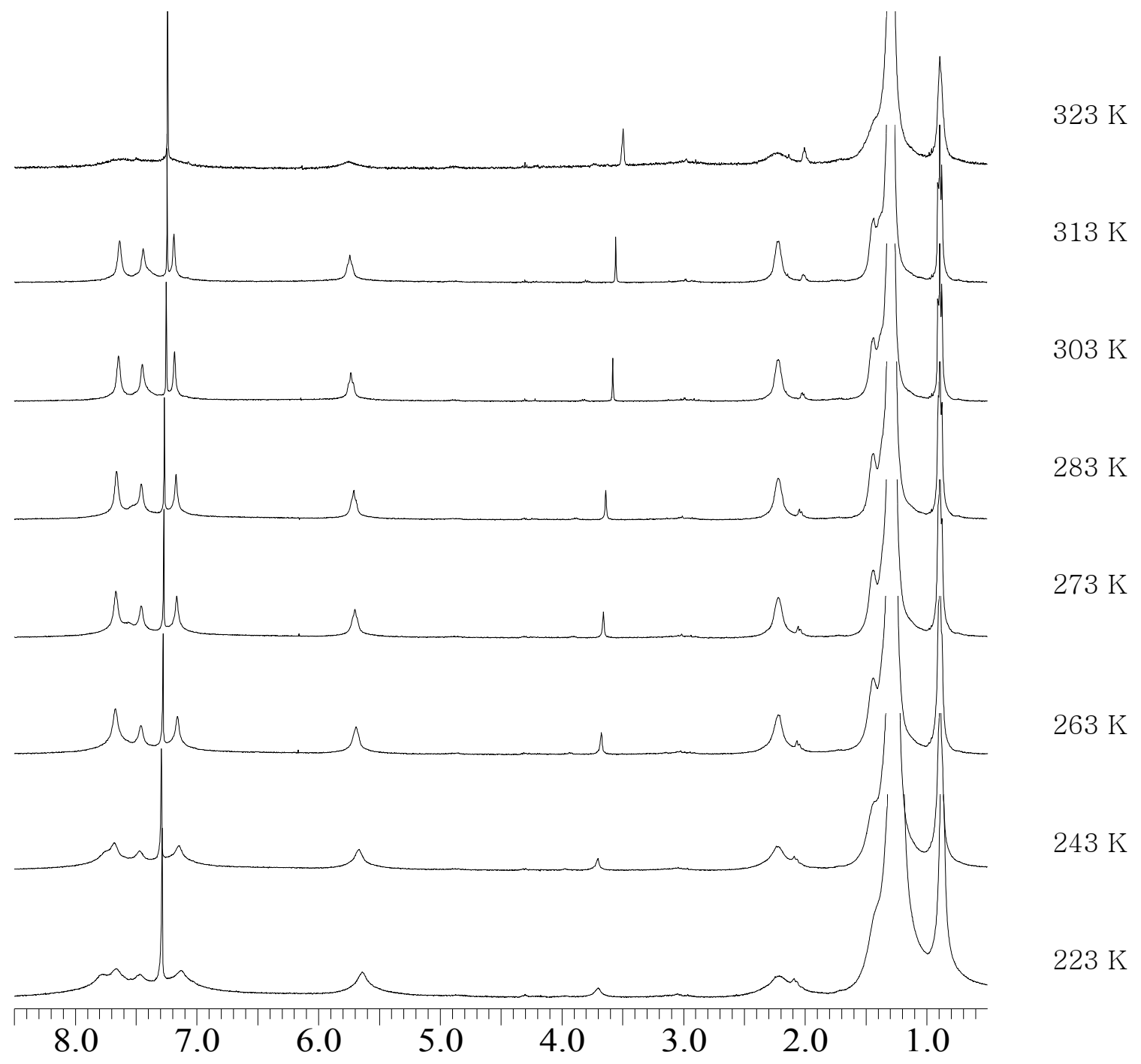

Figure 5. The ${ }^{1} \mathrm{H}$ NMR spectra of Benzimidazole Cavitand 5.4MeOH in $\mathrm{CDCl}_{3}$. 


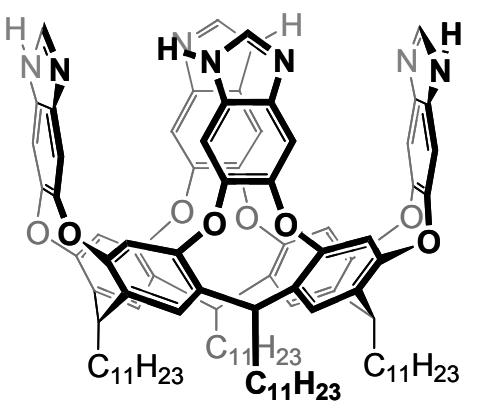

5<smiles>Cc1ccc(NC(=O)c2ccc(C)cc2)cc1</smiles>

6

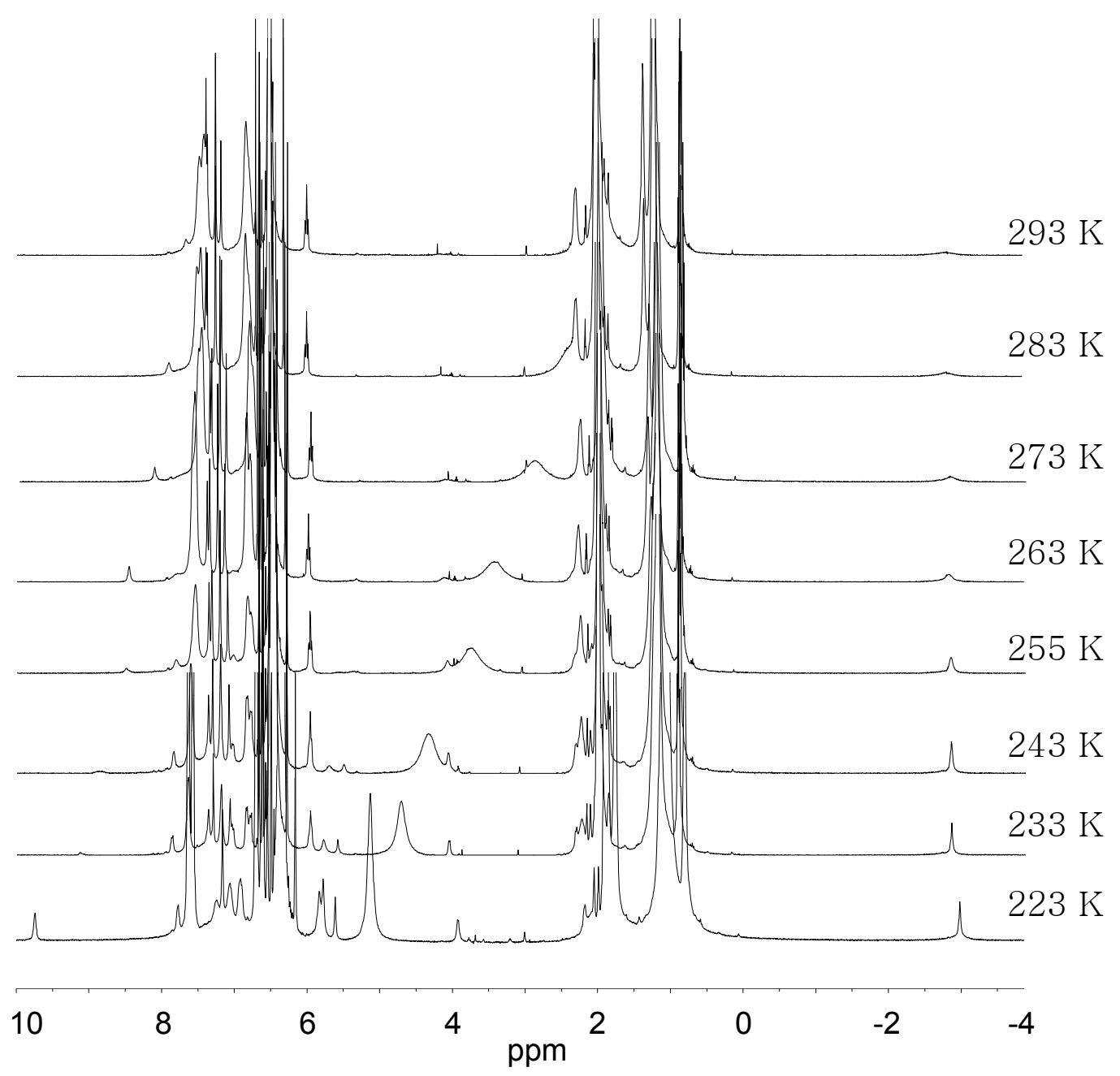

Figure 6. ${ }^{1} \mathrm{H}$ NMR Spectra of Benzimidazole Cavitand 5 and 4-Methyl- $N$-4-tolylbenzamide 6 in $\mathrm{CD}_{3} \mathrm{OD} /$ mesitylene- $_{12}(1: 19, \mathrm{v} / \mathrm{v})$. 


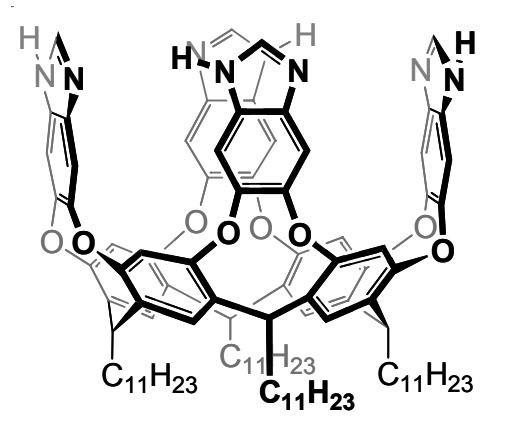

5<smiles>Cc1ccc(NC(=O)c2ccc(C)cc2)cc1</smiles>

6

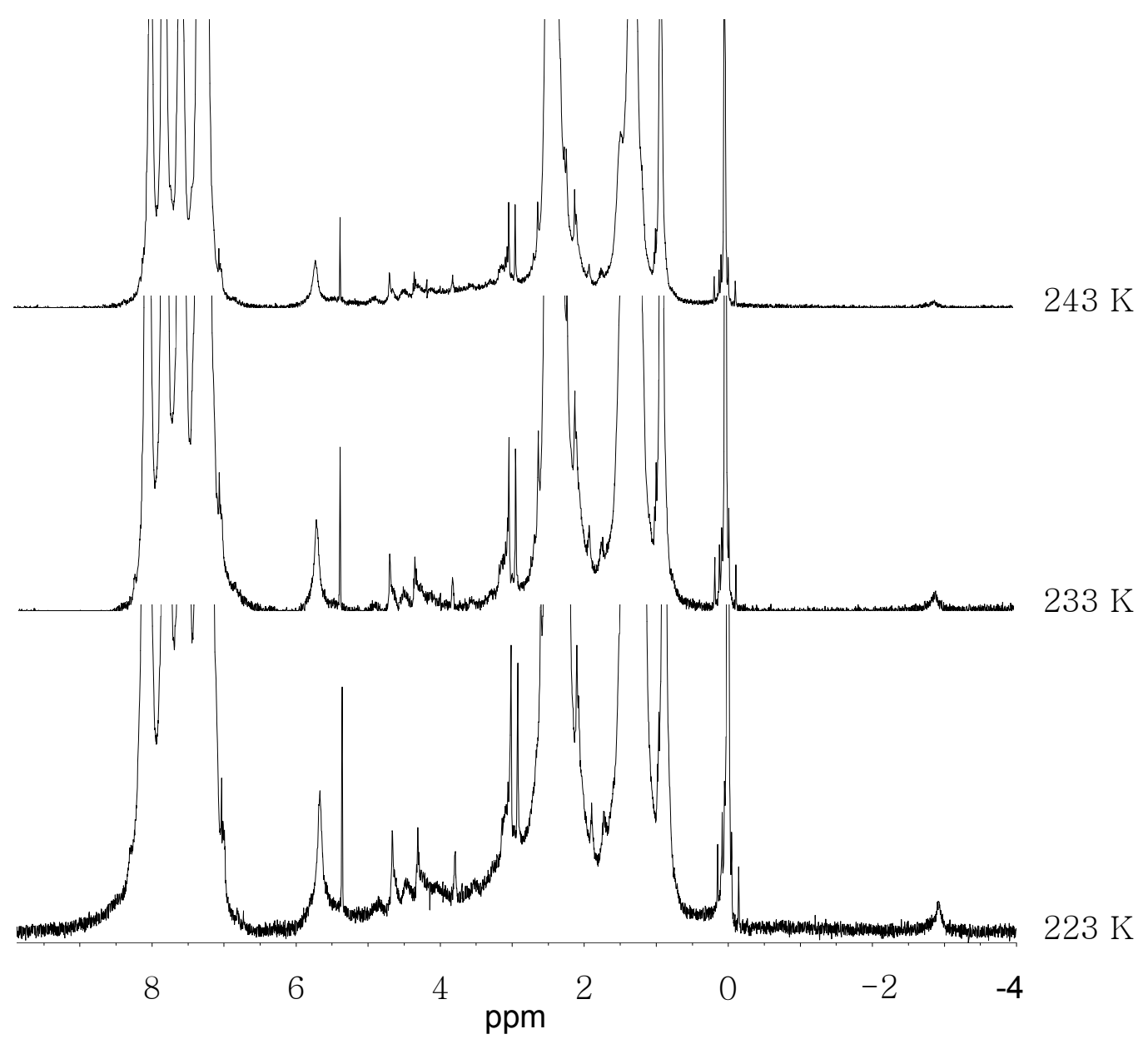

Figure 7. ${ }^{1} \mathrm{H}$ NMR Spectra of Benzimidazole Cavitand 5 and 4-Methyl- $N$-4-tolylbenzamide 6 in water-saturated $\mathrm{CDCl}_{3}$. 

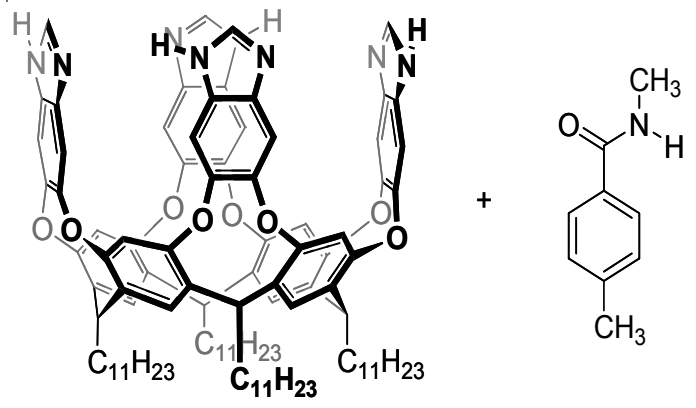

5

7

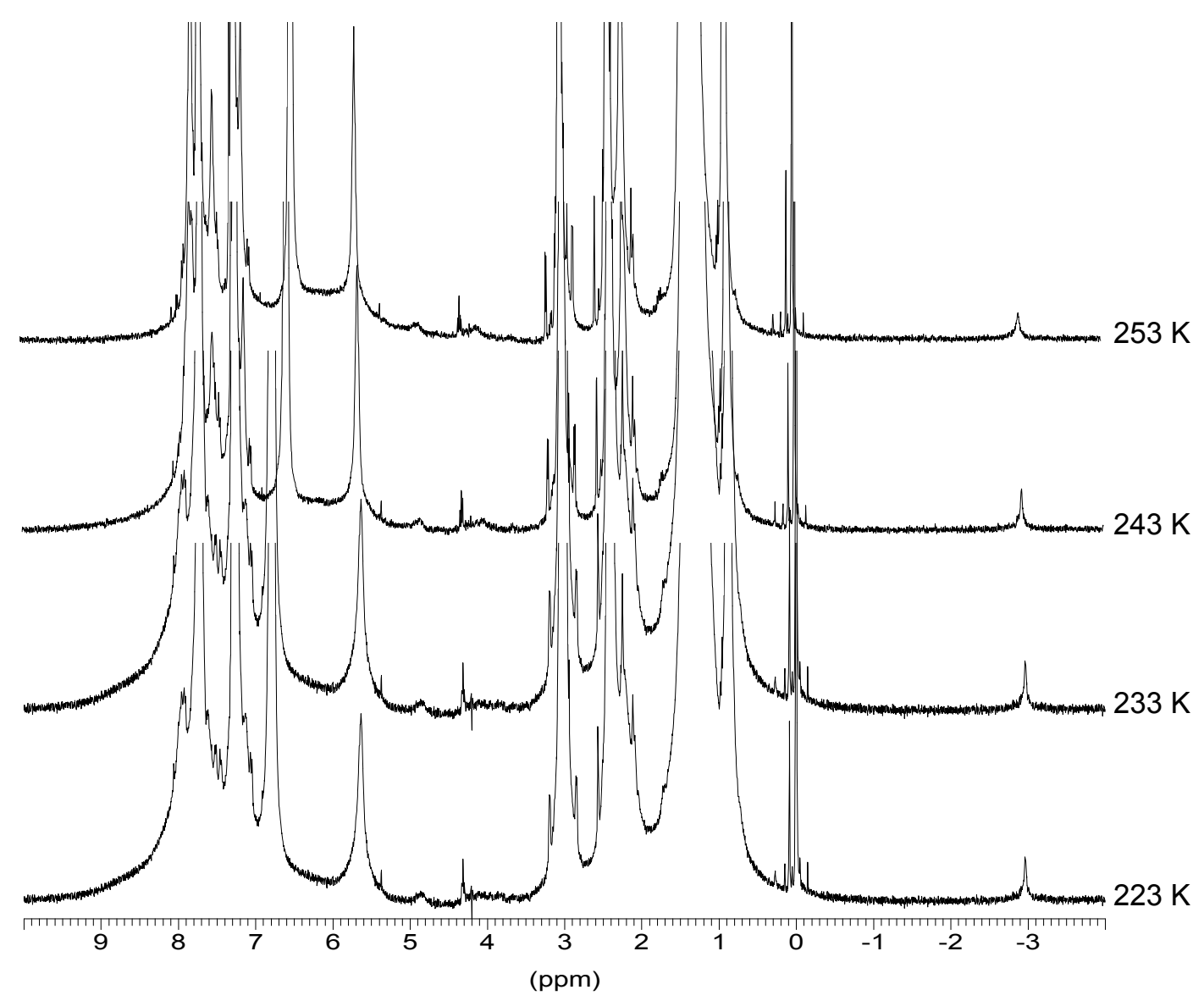

Figure 8. ${ }^{1} \mathrm{H}$ NMR Spectra of Benzimidazole Cavitand 5 and N,4-Dimethylbenzamide 7 in watersaturated $\mathrm{CDCl}_{3}$. 


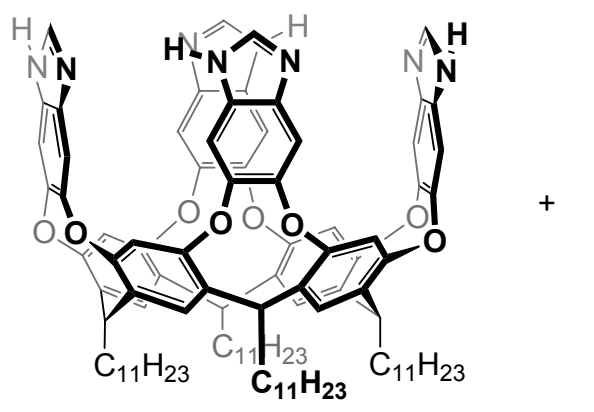

5<smiles>CC(=O)Nc1ccc(C)cc1</smiles>

8

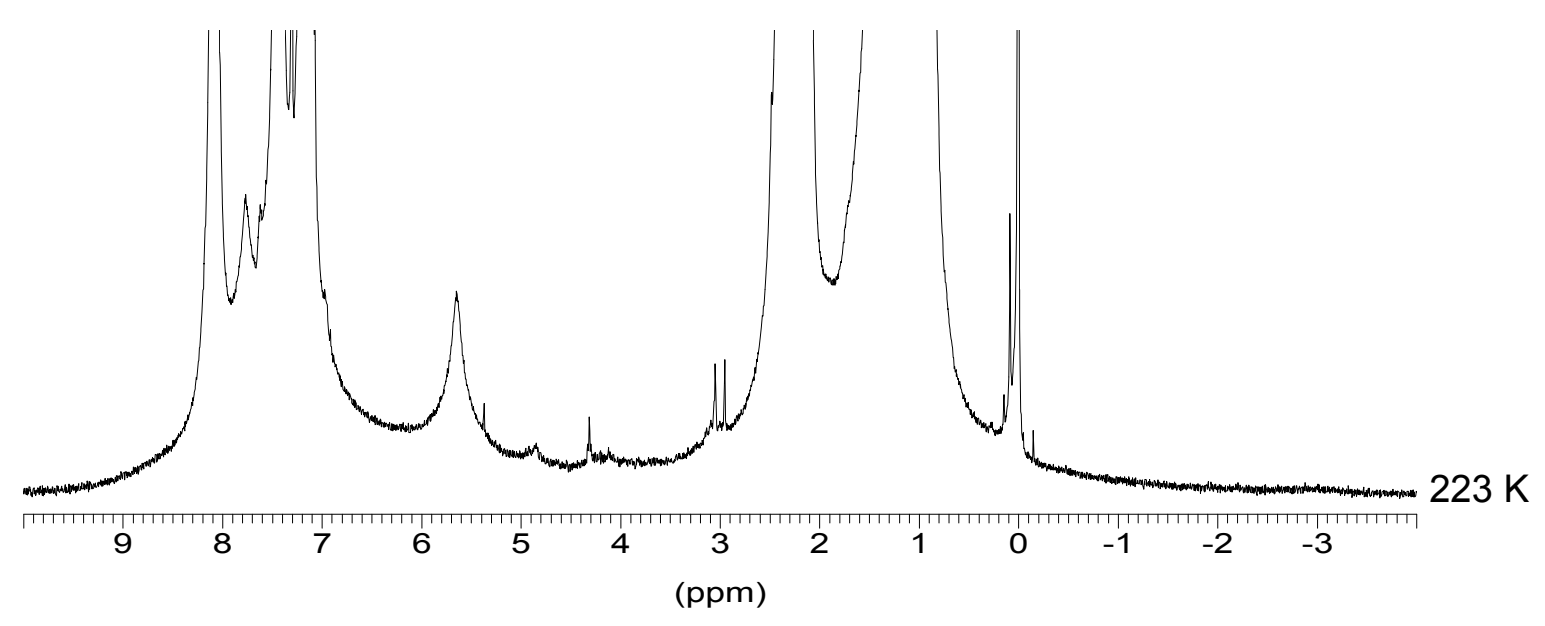

Figure 9. ${ }^{1} \mathrm{H}$ NMR Spectra of Benzimidazole Cavitand 5 and $N$-4-tolylacetamide 8 in watersaturated $\mathrm{CDCl}_{3}$. 